\title{
Extraction socket sealing using palatal gingival grafts and resorbable collagen membranes
}

\author{
Sang-Yun Kim ${ }^{1}$, Young-Kyun Kim ${ }^{1,2^{*}}$ D, Hyun-Suk Kim ${ }^{1}$, Pil-Young Yun ${ }^{1}$, Su-Gwan Kim ${ }^{3}$ and Yong-Hun Choi ${ }^{4}$
}

\begin{abstract}
Background: Socket sealing surgery is performed for the preservation of the form and volume of the soft tissue by covering the resulting socket with autogenous soft tissue graft or membrane barriers. This procedure is usually necessary to improve the esthetic results of the maxillary anterior or premolar areas.

Methods: This study retrospectively investigated cases involving the open membrane technique or socket sealing surgery with a palatal gingival graft or collagen membrane where implant placement and bone grafting were performed immediately after tooth extraction. From January 2005 to December 2008, socket sealing surgery was performed in 24 patients, and 25 implants were placed.

Results: All implants were successful in the follow-up period. In the palatal gingival graft group, the mean marginal bone loss was $1.17 \mathrm{~mm}$ during the mean follow-up period of 81.0 months. In the collagen membrane group, the mean marginal bone loss was $1.23 \mathrm{~mm}$ during the mean follow-up period of 76.9 months. There was no significant difference between the two groups.
\end{abstract}

Conclusions: Consequently, socket sealing surgery is effective at minimizing the loss of soft tissue and alveolar bone.

Keywords: Membrane, Palatal gingival graft, Socket sealing

\section{Background}

After tooth extraction, alveolar bone is destroyed and an atrophic alveolar ridge is formed $[1,2]$. So, the preservation of hard and soft tissues is very important to allow for restoration with prosthetics and implants. Mucoperiosteal flap elevation is generally required to facilitate filling with the bone graft and other materials, which is required to perform the primary suture for extraction socket preservation. Flap elevation induces bone resorption and causes other problems that are attributable to soft tissue retraction and cicatrization, both of which are esthetic problems [3]. Furthermore, the flap that is formed to cover the extraction socket, either partially or completely, may cause a retraction of the gingival

\footnotetext{
* Correspondence: kyk0505@snubh.org

${ }^{1}$ Department of Oral and Maxillofacial Surgery, Section of Dentistry, Seoul National University Bundang Hospital, 300 Gumi-dong, Bundang-gu, Seongnam, Gyeonggi-do, South Korea

${ }^{2}$ Department of Dentistry \& Dental Research Institute, School of Dentistry, Seoul National University, Seoul, South Korea

Full list of author information is available at the end of the article
}

margin of adjacent teeth, a loss of the interdental papilla, and the destruction of the keratinized gingiva [4]. Therefore, there have been reports on ridge preservation or socket sealing surgeries, in which various graft materials have been used to prevent the destruction of the tissues surrounding the extraction socket [5-7]. Among these surgeries, the socket sealing surgery preserves the shape and mass of the surrounding soft tissue. This is accomplished by placing an implant and performing the bone graft without dissecting the flap during the tooth extraction but covering the upper part with an autogenous soft tissue graft or a membrane. This surgery is mainly applied in cases of esthetic concern, such as the maxillary anterior or the premolar regions.

A previous study has shown that natural soft tissue healing at 6 weeks after tooth extraction was superior when socket sealing surgery was performed in the extraction socket along with the bone graft [8]. If the upper part of extraction socket was covered by soft tissue or membrane, there was a risk of complications such as 
necrosis or wound dehiscence. Therefore, vascularization is very important [9]. Another study reports that the use of a membrane to cover the extraction socket can have negative effects due to wound dehiscence, membrane exposure, and premature shedding $[10,11]$. According to a recent study, however, intentional exposure of the resorbable membrane did not have a negative effect on guided bone regeneration (GBR) [12].

Other studies showed that extraction technique itself induces alveolar bone resorption regardless of whether the socket is treated with free gingival graft or bone graft [13]. There was also a study that the ridge preservation technique using xenograft in combination with collagen membrane significantly reduced the alveolar bone resorption after tooth extraction compared to extraction alone [14].

The authors conducted this study to examine the clinical prognosis and treatment results of cases where socket sealing was performed using the open membrane technique or a palatal gingival graft technique to prevent buccolingual soft tissue recession and to perform GBR. In these strategies, the implant is placed immediately after tooth extraction to allow the bone graft in the surrounding bony defect.

\section{Methods}

\section{Patients}

The authors conducted a retrospective study of socket sealing surgery cases in patients who received implant treatment in the Seoul National University Bundang Hospital between January 2006 and December 2008. This study was conducted under IRB approval (B-1206160-111) granted by the Seoul National University Bundang Hospital. Socket sealing surgery was performed in 24 patients, with a total of 25 implants placed. Palatal tissue grafting was performed in 11 implants (anterior teeth 7, posterior teeth 4) of 11 patients (males 5, females 6). Nine implants were placed immediately after extraction, 2 implants were placed secondarily. For the palatal tissue grafting, a free graft was used in 10 of the cases and a pedicled graft was used for 1 case. A resorbable collagen membrane was used in 14 implants (anterior teeth 7, posterior teeth 7) of 13 patients (males 2, females 11). Ten implants were placed immediately after extraction, and 4 implants were placed secondarily. Seven Ossix ${ }^{\circ}$ (OraPharma, Inc., PA, USA), 5 BioArm (ACE Surgical Supply Company Inc., Brockton, MA, USA), and 2 BioGide (Geistlich Biomaterials, Inc., 6110 Wolhusen, Switzerland) resorbable collagen membranes were used.

\section{Measurement of marginal bone loss}

Distances between implant shoulder and the first visible bone-implant contact $(\mathrm{mm})$ were measured using PACS software (INFINITT PACS 3.0.9.1, Seoul, Korea). The clinician scored two marks designating where the crestal bone intersected the implant body as shown on the software. Mesial and distal bone losses of the implant were measured to calculate the mean marginal bone loss. Change in crestal bone height of each implant was calculated from the differences between the initial and final measurements from standardized periapical radiographs. The magnification rate was taken into consideration to compensate proportional differences between the real implant length and the length shown on the radiographs.

\section{Complications, success, and survival rate}

The complications occurred during the follow-up period after implant placement were investigated. The Albrektsson (1998) definitions of success criteria for implants were used: (1) no persistent pain, discomfort, or paresthesia; (2) no abscess around the implant; (3) no mobility; (4) no radiolucency around the implant; and (5) less than $1 \mathrm{~mm}$ of annual marginal bone loss after prosthetic loading.

The survival rate was defined as the percentage of implants that remained until the final examination [15].

\section{Statistics}

To statistically analyze the amount of marginal bone loss and complication rate between the two groups, independent sample $t$ test was used (SPSS Inc., Chicago, IL, USA).

\section{Results and discussion \\ Patients}

Twenty-five implants were placed in a total of 24 patients, and the mean follow-up period was 78.7 months. Complications occurred in 8 implants (dehiscence $n=7$, peri-implantitis $n=1$ ), all minor and treatable. Overall success and survival rates were $100 \%$. The mean marginal bone loss was $1.21 \pm 0.13 \mathrm{~mm}$ at the final visit.

In palatal graft group, the patients' age ranged from 23 to 62 years with a mean age of 46.7 years. Follow-up period ranged from 16.7 to 123.5 months with a mean of 81.0 months. In the resorbable membrane group, the patients' age ranged from 23 to 76 years with a mean age of 50.5 years. Follow-up period ranged from 14.4 to 122.1 months with a mean of 76.9 months. When palatal tissue grafts were used, the marginal bone loss was 1.17 $\pm 0.13 \mathrm{~mm}$. When a resorbable membrane was used, the marginal bone loss was $1.23 \pm 0.14 \mathrm{~mm}$. Significant difference was not found between the two groups $(p>.05)$.

Both groups showed $100 \%$ success and survival rates (Tables 1 and 2). In the palatal graft group, there were two cases of wound dehiscence and one case of periimplantitis, resulting in a total of $27.3 \%$ of complication rate. In resorbable membrane group, there were five cases of wound dehiscence (35.7\%). There was no statistically significant difference in the incidence of complications between the two groups $(p>.05)$. 
Table 1 Socket sealing with palatal tissue grafting

\begin{tabular}{|c|c|c|c|c|c|c|c|c|c|c|c|c|c|}
\hline Case & A & S & Area & Surg. & Implant & $\mathrm{D}$ & L & Bone graft & Types of palatal tissue & Comp & Healing & $\mathrm{F} / \mathrm{U}$ & $\mathrm{BL}$ \\
\hline 1 & 52 & $\mathrm{~F}$ & $\# 24$ & Ext. IP & Implantium & 3.8 & 14 & Biocera & Free & No & 5.5 & 114.2 & 1.15 \\
\hline 2 & 61 & $\mathrm{~F}$ & $\# 22$ & Ext. IP & GS ॥ & 3.5 & 15 & Bio-Oss & Free & No & 5.6 & 16.7 & 1.2 \\
\hline 3 & 23 & M & $\# 25$ & Ext. IP & GS ॥ & 4 & 15 & Bio-Oss & Free & WD & 6.4 & 45.3 & 1 \\
\hline 4 & 49 & $\mathrm{~F}$ & $\# 15$ & Ext. IP & Implantium & 3.8 & 14 & Biocera & Free & WD & 3.5 & 99.2 & 1 \\
\hline 5 & 40 & $\mathrm{~F}$ & $\# 12$ & Ext.DP & Implantium & 3.4 & 14 & Biocera & Pedicled & No & 4.3 & 123.5 & 1.1 \\
\hline 6 & 47 & $\mathrm{~F}$ & $\# 22$ & Ext. IP & TiUnite & 3.3 & 15 & Bio-Oss & CT & No & 5.0 & 120.6 & 1.3 \\
\hline 7 & 34 & M & $\# 11$ & Ext. IP & GS ॥ & 5 & 15 & $\begin{array}{l}\text { Ortholl } \\
\text { Bio-Oss }\end{array}$ & Free & No & 5.5 & 78.0 & 1 \\
\hline 8 & 58 & M & $\# 25$ & Ext. IP & GS ॥ & 4 & 13 & Biocera & Free & No & 4.2 & 37.0 & 1.25 \\
\hline 9 & 62 & M & $\# 22$ & Ext. IP & US ॥ & 3.75 & 15 & BBP & Free & No & 5.3 & 86.3 & 1.3 \\
\hline 10 & 27 & M & $\# 22$ & Ext. IP & Implantium & 3.8 & 14 & Bio-Oss & Free & PI & 5.1 & 105.2 & 1.35 \\
\hline 11 & 61 & F & $\# 23$ & Ext. IP & GS III & 4.5 & 15 & Biocera & Free & No & 1.2 & 65.4 & 1.25 \\
\hline
\end{tabular}

$A$ age, $S$ sex, $D$ diameter, $L$ length, Comp. complication, $W D$ wound dehiscence, $P I$ peri-implantitis, healing healing period between the first implant surgery and the prosthetic treatment (months), F/U follow-up (months), BL bone loss (mm), surg. type of surgery (Ext. extraction, IP immediate implant placement, DP delayed placement), GS II (OSSTEM IMPLANT Co., Busan, Korea), GS III (OSSTEM IMPLANT Co., Busan, Korea), US II (OSSTEM IMPLANT Co., Busan, Korea), Implantium

(Dentium, Seoul, Korea), TiUnite (Nobel Biocare, Gthenburg, Sweden)

Table 2 Socket sealing using resorbable collagen membranes

\begin{tabular}{|c|c|c|c|c|c|c|c|c|c|c|c|c|c|}
\hline Case & $A$ & S & Area & Surg. & Implant & $D$ & L & Bone graft & Types of membrane & Comp & Healing & $F / U$ & $B L$ \\
\hline 1 & 57 & $\mathrm{~F}$ & $\# 35$ & $\begin{array}{l}\text { Ext. } \\
\mathbb{I P}\end{array}$ & Implantium & 3.8 & 14 & Bio-Oss & Ossix & No & 2.5 & 122.1 & 1.25 \\
\hline 2 & 23 & $\mathrm{~F}$ & \#24 & $\begin{array}{l}\text { Ext. } \\
\mathbb{I P}\end{array}$ & GS ॥ & 3.5 & 15 & AutoBT & Ossix & No & 4.9 & 45.2 & 1.45 \\
\hline 3 & 72 & M & $\# 11$ & $\begin{array}{l}\text { Ext. } \\
\mathbb{I P}\end{array}$ & Implantium & 4.3 & 12 & Bio-Oss & Ossix & WD & 7.7 & 100 & 1.1 \\
\hline 4 & 25 & $\mathrm{~F}$ & \#22 & $\begin{array}{l}\text { Ext. } \\
\mathbb{I P}\end{array}$ & GS ॥ & 3.5 & 15 & Bio-Oss & Ossix & No & 5.2 & 55.3 & 1.1 \\
\hline 5 & 50 & $\mathrm{~F}$ & $\begin{array}{l}\# 26 \\
\# 27\end{array}$ & $\begin{array}{l}\text { Ext. } \\
\text { DP }\end{array}$ & $\begin{array}{l}\text { Oneplant } \\
\text { Oneplant }\end{array}$ & $\begin{array}{l}4.3 \\
4.3\end{array}$ & $\begin{array}{l}13 \\
11.5\end{array}$ & $\begin{array}{l}\text { Bio-Oss } \\
\text { Ortho II }\end{array}$ & $\begin{array}{l}\text { Ossix } \\
\text { Ossix }\end{array}$ & $\begin{array}{l}\text { WD } \\
\text { WD }\end{array}$ & $\begin{array}{l}5.6 \\
5.6\end{array}$ & $\begin{array}{l}112.9 \\
112.9\end{array}$ & $\begin{array}{l}1.3 \\
1.1\end{array}$ \\
\hline 6 & 36 & $\mathrm{~F}$ & $\# 11$ & $\begin{array}{l}\text { Ext. } \\
\text { DP }\end{array}$ & 31 & 4 & 13 & Bio-Oss & Bio-Gide & No & 6.7 & 65.1 & 1.2 \\
\hline 7 & 42 & $\mathrm{~F}$ & $\# 14$ & $\begin{array}{l}\text { Ext. } \\
\text { DP }\end{array}$ & Oneplant & 4.3 & 13 & BBP & Bioarm & No & 4.4 & 76.0 & 1.35 \\
\hline 8 & 50 & M & $\# 22$ & $\begin{array}{l}\text { Ext. } \\
\mathbb{I P}\end{array}$ & GS III & 4 & 13 & Biocera & Bioarm & WD & 18 & 75.4 & 1.4 \\
\hline 9 & 52 & $\mathrm{~F}$ & $\# 17$ & $\begin{array}{l}\text { Ext. } \\
\mathbb{I P}\end{array}$ & GS ॥ & 5 & 13 & Biocera & Bioarm & No & 3.4 & 96.1 & 1.25 \\
\hline 10 & 47 & $\mathrm{~F}$ & $\# 21$ & $\begin{array}{l}\text { Ext. } \\
\mathbb{I P}\end{array}$ & Implantium & 4.3 & 14 & Biocera & Bioarm & No & 3.4 & 73.6 & 1.3 \\
\hline 11 & 57 & F & $\# 15$ & $\begin{array}{l}\text { Ext. } \\
\mathbb{I P}\end{array}$ & CMI & 4 & 13 & Biocera & Ossix & No & 4.2 & 72.2 & 1 \\
\hline 12 & 76 & $\mathrm{~F}$ & $\# 13$ & $\begin{array}{l}\text { Ext. } \\
\mathbb{I P}\end{array}$ & GS III & 4 & 13 & AlloBT & Bio-Gide & WD & 4.7 & 56.0 & 1.1 \\
\hline 13 & 69 & F & $\# 12$ & $\begin{array}{l}\text { Ext } \\
\text { IP }\end{array}$ & GS ॥ & 4 & 15 & Biocera & Bioarm & No & 4.0 & 14.4 & 1.4 \\
\hline
\end{tabular}

$A$ age, $S$ sex, $D$ diameter, $L$ length, Comp. complication, WD wound dehiscence, $P I$ peri-implantitis, healing healing period between the first implant surgery and the prosthetic treatment (months), F/U follow-up (months), BL bone loss (mm), surg: type of surgery (Ext. extraction, IP immediate implant placement, RP ridge preservation, DP delayed placement), GS II (OSSTEM IMPLANT Co., Busan, Korea), GS III (OSSTEM IMPLANT Co., Busan, Korea), US II (OSSTEM IMPLANT Co., Busan, Korea), Implantium (Dentium, Seoul, Korea), TiUnite (Nobel Biocare, Gthenburg, Sweden) 


\section{Case reports}

Case 1: socket sealing surgery using a free palatal gingival graft (Fig. 1) (Table 1, case 6)

A 47-year-old female patient visited the hospital complaining of pain in her left maxillary lateral incisor. Mild tooth mobility and a cervical fracture were found, and a radiolucent periapical lesion was observed in panoramic radiograph. As a result, a plan was established to place an implant immediately following tooth extraction. On September 29, 2005, a flapless extraction was performed and the extraction socket was probed and $5 \mathrm{~mm}$ labial bony dehiscence was observed. Drilling was performed on the palatal side before the implant (Nobelbiocare TiUnite, $3.3 \mathrm{~mm}$ in diameter, $15 \mathrm{~mm}$ in length) was placed and connected with a cover screw. Osstell Mentor (Integration Diagnostics AB, Göteberg, Sweden) was used to measure its primary stability, which had implant stability quotient (ISQ) value of 72 . A periosteal elevator was used to form a pouch in the upper part of the labial cortical bone before the Bio-Oss (Geistlich Pharma AG, Wolhausen, Switzerland) was grafted. The free palatal gingiva was then taken before the upper part of the implant was covered and sutured to install a temporary flipper. Post-surgical wound healing after the surgery was favorable, and the implant was exposed in the second surgery on February 27, 2006. Using the Osstell Mentor for measurement, the implant's secondary stability (ISQ) was 73. On April 11, 2006, the final prosthesis was installed and it remained stable even after 121 months of function.

\section{Case 2: socket sealing using a pedicled palatal gingival graft (Fig. 2) (Table 1, case 5)}

A 40-year-old female patient visited the hospital with mobility and pain in right maxillary lateral incisor. Clinical and radiological examinations revealed severe destruction of the surrounding alveolar bone. On July
28, 2005, extraction and socket curettage were performed before Biocera (Osscotec, Seoul, Korea) was transplanted. A pedicled flap was formed on palatal side to maintain labial soft tissue contours. The flap was then coronally positioned towards the extraction socket prior to suturing. Five months later, a palatal crestal incision and a flap elevation were performed before implant placement. A bone graft (Orthoblast II: Orthobiologics, Irvine, USA) was placed on the labial side of the implant, a collagen membrane (Ossix: Orapharma Inc., Louis Drive Warminster, PA, USA) was covered, and the wound was sutured. On May 9, 2006, a second surgery was performed. The final prosthesis was installed on June 27, 2006. This prosthesis remained stable even after 124 months of function.

\section{Case 3: socket sealing with a resorbable collagen membrane (Fig. 3) (Table 2, case 3)}

A 72-year-old male patient visited the hospital due to a right maxillary central incisor fracture. A periapical lesion was not found, and his periodontal condition was favorable. On March 6, 2007, a flapless atraumatic extraction was performed and the socket was probed. According to the probing results, the existing labial bone destruction was severe. Mucoperiosteal flap elevation was performed before implant placement. Bio-Oss was grafted to restore the labial dehiscence defect. A collagen membrane (Ossix) was then covered, and the wound was sutured. Flap undermining was not performed to maintain the labial soft tissue contour. The membrane where the upper part of the implant was covered was intentionally left exposed. The exposed membrane was absorbed over time, leading to favorable secondary healing. After 6 months, the secondary surgery was performed. The final prosthesis was installed on November 29, 2007. This prosthesis remained stable even after 100 months of function.

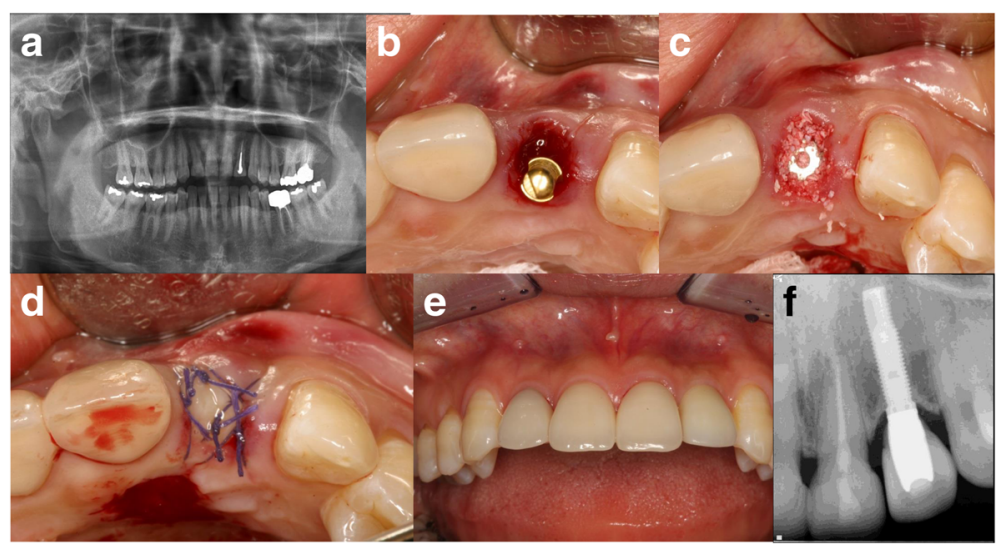

Fig. 1 Socket sealing surgery using a free palatal gingival graft. a The first panoramic radiograph. b Implant placement. c Bone graft. d Palatal free gingival graft. e Intraoral view 60 months after final prosthesis placement. f Periapical radiograph 84 months after final prosthesis placement 


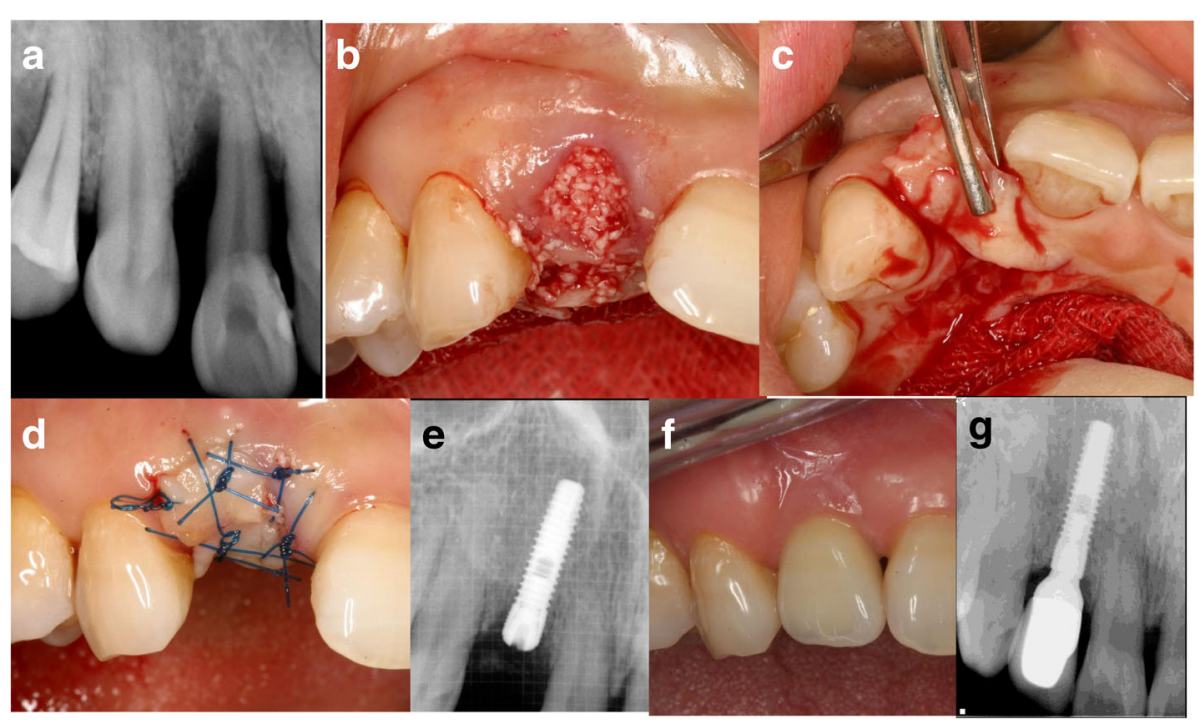

Fig. 2 Socket sealing using a pedicled palatal gingival graft. a The first periapical view. b Extraction and bone graft. c, d Pedicled palatal flap. e Periapical radiograph after implant placement. f Intraoral view 58 months after final prosthesis placement. $\mathbf{g}$ Periapical radiograph 93 months after final prosthesis placement

Socket sealing surgery is performed for extraction socket preservation when an implant is placed immediately following tooth extraction. Because a mucoperiosteal flap is not formed, this surgery is favorable because the alveolar bone and its surrounding soft tissues can be preserved as much as possible. In this study, an open membrane technique and a palatal gingival graft technique were used, with the aim of preserving as much keratinized gingival tissue as possible. However, the benefits of keratinized gingival preservation remain controversial. Some studies have stated that there is insufficient evidence for the importance of keratinized gingival preservation [16]. However, other studies have indicated that preservation of the vestibule and its associated keratinized gingiva can improve oral hygiene and minimize the risk of bleeding on probing, recession, plaque-induced peri-implantitis in implant, and restoration in the future [17-19]. As an attempt to cover the grafted extraction socket and to prevent bacterial colonization from salivary contamination, free gingival

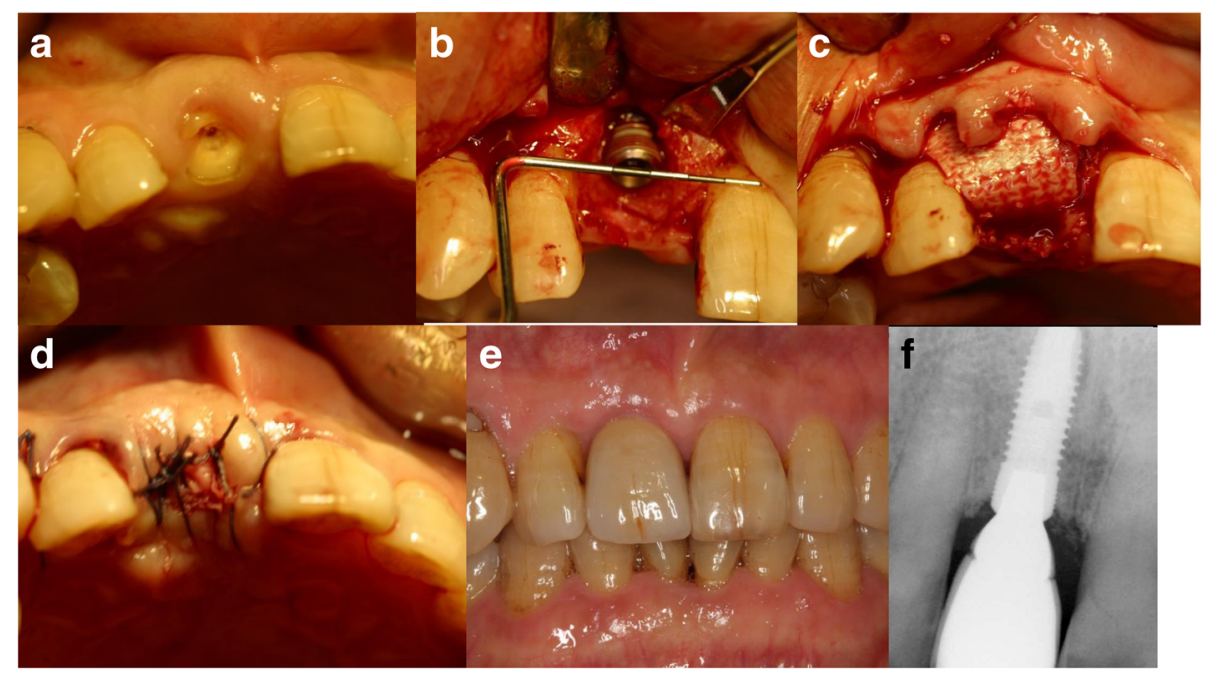

Fig. 3 Socket sealing with a resorbable collagen membrane. a The first visit. b Implant placement. c Bio-Oss was transplanted to the labial dehiscence defect before the collagen membrane (Ossix) was covered and the wound was sutured. $\mathbf{d}$ Flap undermining was not performed to promote labial soft tissue contour maintenance, and the membrane where the upper part of implant was covered was intentionally left exposed. e Intraoral view 48 months after final prosthesis placement. f Periapical radiograph 72 months after final prosthesis placement 
grafts were introduced in 1994 for socket sealing [20] However, the reported failure rate was $50 \%$ or higher (26\% for total necrosis and 31\% for partial necrosis) [9]. For this reason, a new procedure using a combined epithelialized-subepithelial graft was introduced [21]. The free gingival graft used in this study demonstrated that wound dehiscence occurred in two cases, but that healing was successful in all cases. All assessed grafts functioned successfully until the final prosthesis was loaded.

Wilson et al. presented clinical results for cases where a connective tissue membrane was used for immediate implant placement. They reported excellent osseointegration results with immediate implant placement in horizontal bone defects of $4 \mathrm{~mm}$ or higher [22]. Recently, Stimmelmayr et al. reported bone grafting to rebuild buccal alveolar defects at the same time that the tooth is extracted, combined with a soft tissue graft to seal the socket, showed promising results and could be an alternative treatment to delayed hard tissue grafting [23].

Zubillanga et al. attempted to use primary sutures for ridge preservation in all cases. They found that though $45 \%$ of the membrane was eventually exposed, infections or other clinical complications were not observed in any cases [24]. Furthermore, Engler-Hamm et al. compared the use of primary sutures made of resorbable membranes with intentional exposure during ridge preservation. They reported that the discomfort and swelling following surgery was less severe when the membrane was intentionally exposed without flap dissection than when the primary suture was performed through flap dissection. They also found that the results were more favorable when keratinized gingival tissues were preserved, and no differences in bone resorption were observed [25]. In this study, the resorbable collagen membrane was intentionally exposed to allow for socket sealing. All of the cases assessed here had successful results with minimal observed complications. Unlike previous studies that showed the resorbable membrane as a reservoir of bacterial propagation resulting in infection and eventually failure of bone graft, there was not a single case of failure due to infection when membranes were intentionally exposed. This means that appropriate antibiotic therapy and disinfection could sufficiently reduce the risk of infection, and extraction socket sealing surgery using resorbable collagen membrane can show clinical results similar to those of palatal gingival graft.

In this study, socket sealing surgery was performed to prevent soft tissue retraction in regions of esthetic importance, such as the maxillary anterior region or the premolar region. In the average observation period of 78.7 \pm 31.4 months, the post-extraction loss of marginal bone was found to be $1.21 \pm 0.13 \mathrm{~mm}$ on average, indicating that a stable state was maintained. In conclusion, palatal gingival grafts and open membrane techniques using resorbable membranes can be used to produce clinically favorable results in terms of soft tissue preservation in regions of esthetic importance (Additional file 1).

\section{Conclusions}

Consequently, socket sealing surgery is effective at minimizing the loss of soft tissue and alveolar bone.

\section{Additional file}

Additional file 1: Case form and result of data. (XLSX $31 \mathrm{~kb}$ )

\section{Abbreviations}

GBR: Guided bone regeneration; ISQ: Implant stability quotient

\section{Acknowledgements}

Not applicable.

Funding

Not applicable.

Availability of data and materials

The dataset supporting the conclusions of this article is included within the article and in Additional file 1.

\section{Authors' contributions}

KSY participated in data collection and wrote the manuscript. KHS, YPY, KSG, and $\mathrm{CYH}$ participated in the study design and performed the statistical analysis. KYK participated in the study design and coordination and helped to draft the manuscript. All authors read and approved the final manuscript.

\section{Authors' information}

All of the authors have no affiliations with or involvement in any organization or entity with any financial interest or non-financial interest in this manuscript. This manuscript represents original works and is not being considered for publication elsewhere.

Ethics approval and consent to participate

This study was approved by the Institutional Review Board of Seoul National University Bundang Hospital (B-1206-160-111).

\section{Consent for publication}

Written informed consent was obtained from the patients for publication of this research and accompanying images.

\section{Competing interests}

The authors declare that they have no competing interests.

\section{Publisher's Note}

Springer Nature remains neutral with regard to jurisdictional claims in published maps and institutional affiliations.

\section{Author details}

${ }^{1}$ Department of Oral and Maxillofacial Surgery, Section of Dentistry, Seoul National University Bundang Hospital, 300 Gumi-dong, Bundang-gu, Seongnam, Gyeonggi-do, South Korea. ${ }^{2}$ Department of Dentistry \& Dental Research Institute, School of Dentistry, Seoul National University, Seoul, South Korea. ${ }^{3}$ Department of Oral and Maxillofacial Surgery, School of Dentistry, Chosun University, Gwangju, South Korea. ${ }^{4}$ Department of Conservative Dentistry, Seoul National University Bundang Hospital, Seongnam, South Korea. 
Received: 13 November 2017 Accepted: 15 November 2017

Published online: 25 December 2017

\section{References}

1. Bays RA (1986) The pathophysiology and anatomy of edentulous bone loss. In: Fonseca R, Davis WH (eds) Reconstructive preprosthetic oral and maxillofacial surgery. Saunders, Philadelphia, pp 1-17

2. McCall RA, Rosenfeld AL (1991) The influence of residual ridge resorption patterns on implant fixture placement and tooth position. Part 1. Int J Periodontics Restorative Dent 11:9-23

3. Fickl S, Zuhr O, Wachtel H, Stappert CF, Stein JM, Hürzeler MB (2008) Dimensional changes of the alveolar ridge contour after different socket preservation techniques. J Clin Periodontol 35:906-913

4. Landsberg CJ (1997) Socket seal surgery combined with immediate implant placement: a novel approach for single-tooth replacement. Int J Periodontics Restorative Dent 17:140-149

5. Nevins M, Mellonig JT (1994) The advantages of localized ridge augmentation prior to implant placement: a staged event. Int J Periodontics Restorative Dent 14:97-111

6. Kadkhodazadeh M, Ghasemianpour M, Soltanian N, Sultania GR, Ahmadpour S, Amid R (2015) Effects of fresh mineralized dentin and cementum on socket healing: a preliminary study in dogs. J Korean Assoc Oral Maxillofac Surg 41(3):119-123

7. Evaian Cl, Cutler S (1994) Autogenous gingival grafts as epithelial barrier for immediate implants: case reports. J Periodontol 65:201-210

8. Jung R, Siegenthaler D, Hammerle C (2004) Postextraction tissue management: a soft tissue punch technique. Int J Periodontics Restorative Dent 24:545-553

9. Tal H (1999) Autogenous masticatory mucosal grafts in extraction socket seal procedures: a comparison between sockets grafted with de mineralized freeze-dried bone and deproteinized bovine mineral. Clin Oral Implants Res 10:289-296

10. Oh TJ, Meraw SJ, Lee EJ, Giannobile WV, Wang HL (2003) Comparative analysis of collagen membranes for the treatment of implant dehiscence defects. Clin Oral Implants Res 14:80-90

11. Hammerle CHF, Jung RE, (2003) Bone augmentation by means of barrier membranes. Periodontology 2000 33:36-53

12. Cardaropoli D, Cardaropoli G (2008) Preservation of the postextraction alveolar ridge: a clinical and histologic study. Int J Periodontics Restorative Dent 28:469-477

13. Oghli A, Steveling H (2010) Ridge preservation following tooth extraction: a comparison between atraumatic extraction and socket seal surgery. Quintessence Int 41:605-609

14. Barone A, Aldini NN, Fini M, Giardino R, Calvo Guirado JL, Covani U (2008) Xenograft versus extraction alone for ridge preservation after tooth removal: a clinical and histomorphometric study. J Periodontol 79:1370-1377

15. Zarb GA, Albrektsson T (1998) Consensus report: towards optimized treatment outcomes for dental implants. J Prosthet Dent 80:641

16. Esposito M, Grusovin MG, Maghaireh H, Coulthard P, Worthington HV (2007) Interventions for replacing missing teeth: management of soft tissues for dental implants. Cochrane Database Syst Rev 18:CD006697

17. Warrer K, Buser D, Lang NP, Karring T (1995) Plaque-induced peri-implantitis in the presence or absence of keratinized mucosa. An experimental study in monkeys. Clin Oral Implants Res 6:131-138

18. Bouri A Jr, Bissada N, Al-Zahrani MS, Faddoul F, Nouneh I (2008) Width of keratinized gingiva and the health status of the supporting tissues around dental implants. Int J Oral Maxillofac Implants 23:323-326

19. Zigdon H, Machtei EE (2008) The dimensions of keratinized mucosa around implants affect clinical and immunological parameters. Clin Oral Implants Res 19:387-392

20. Landsberg CJ, Bichacho N (1994) A modified surgical/prosthetic approach for optimal single implant supported crown. Part l--the socket seal surgery. Pract Periodont Aesthet Dent 6:11-17

21. Seibert JS, Louis JV (1996) Soft tissue ridge augmentation utilizing a combination onlay-interpositional graft procedure: a case report. Int J Periodontics Restorative Dent 16:310-321

22. Wilson TG Jr, Carnio J, Schenk R, Cochran D (2003) Immediate implants covered with connective tissue membranes: human biopsies. J Periodontol 74:402-409

23. Stimmelmayr M, Güth JF, Iglhaut $G$, Beuer $F$ (2012) Preservation of the ridge and sealing of the socket with a combination epithelialised and subepithelial connective tissue graft for management of defects in the buccal bone before insertion of implants: a case series. Br J Oral Maxillofac Surg 50:550-555

24. Zubillaga G, Von Hagen S, Simon Bl, Deasy MJ (2003) Changes in alveolar bone height and width following post-extraction ridge augmentation using a fixed bioabsorbable membrane and demineralized freeze-dried bone osteoinductive graft. J Periodontol 74(7):965-975

25. Engler-Hamm D, Cheung WS, Yen A, Stark PC, Griffin T (2011) Ridge preservation using a composite bone graft and a bioabsorbable membrane with and without primary wound closure: a comparative clinical trial. J Periodontol 82:377-387

\section{Submit your manuscript to a SpringerOpen ${ }^{\circ}$ journal and benefit from:}

- Convenient online submission

- Rigorous peer review

- Open access: articles freely available online

- High visibility within the field

Retaining the copyright to your article

Submit your next manuscript at springeropen.com 